\title{
Lurasidone for the Treatment of Irritability Associated with Autistic Disorder
}

\author{
Antony Loebel ${ }^{1} \cdot$ Matthew Brams $^{3} \cdot$ Robert S. Goldman $^{1} \cdot$ Robert Silva $^{1} \cdot$ \\ David Hernandez ${ }^{1} \cdot$ Ling Deng $^{1} \cdot$ Raymond Mankoski $^{1,2} \cdot$ Robert L. Findling $^{4}$
}

Published online: 11 December 2015

(c) The Author(s) 2015. This article is published with open access at Springerlink.com

\begin{abstract}
The aim of this study was to evaluate the shortterm efficacy and safety of lurasidone in treating irritability associated with autistic disorder. In this multicenter trial, outpatients age 6-17 years who met DSM-IV-TR criteria for autistic disorder, and who demonstrated irritability, agitation, and/or self-injurious behaviors were randomized to 6 weeks of double-blind treatment with lurasidone $20 \mathrm{mg} /$ day $(\mathrm{N}=50), 60 \mathrm{mg} /$ day $(\mathrm{N}=49)$, or placebo $(\mathrm{N}=51)$. Efficacy measures included the Aberrant Behavior Checklist Irritability subscale (ABC-I, the primary endpoint) and the Clinical Global Impressions, Improvement (CGI-I) scale, and were analyzed using a likelihood-based mixed model for repeated measures. Least squares (LS) mean (standard error [SE]) improvement from baseline to Week 6 in the ABC-I was not significantly different for lurasidone $20 \mathrm{mg} /$ day $(-8.8$ [1.5]) and lurasidone $60 \mathrm{mg} /$ day $(-9.4[1.4])$ versus placebo $(-7.5$ [1.5]; $p=0.55$ and 0.36 , respectively). CGI-I scores showed significantly greater LS mean [SE] improvement at Week 6 for lurasidone $20 \mathrm{mg} /$ day versus placebo (2.8 [0.2] vs. $3.4[0.2] ; p=0.035$ ) but not for lurasidone $60 \mathrm{mg} /$ day (3.1 [0.2]; $p=0.27$ ). Discontinuation rates due to adverse events were: lurasidone $20 \mathrm{mg} / \mathrm{day}, 4.1 \% ; 60 \mathrm{mg} /$ day, $3.9 \%$; and placebo, $8.2 \%$. Adverse events with an
\end{abstract}

Raymond Mankoski

Raymond.Mankoski@Sunovion.com

Sunovion Pharmaceuticals, Inc., Fort Lee, NJ, USA

2 Sunovion Pharmaceuticals, Inc., 84 Waterford Drive, Marlborough, MA 01752, USA

3 Menninger Department of Psychiatry, Baylor College of Medicine, Houston, TX, USA

4 Child and Adolescent Psychiatry, Kennedy Krieger Institute and Johns Hopkins University, Baltimore, MD, USA incidence $\geq 10 \%$ (lurasidone combined, placebo) included vomiting (18.0, $4.1 \%)$ and somnolence $(12.0,4.1 \%)$. Modest changes were observed in weight and selected metabolic parameters. In this study, once-daily, fixed doses of 20 and $60 \mathrm{mg} /$ day of lurasidone were not demonstrated to be efficacious compared to placebo for the short-term treatment of children and adolescents with moderate-tosevere irritability associated with autistic disorder.

Keywords Autism - Irritability · Lurasidone - Atypical antipsychotic

\section{Introduction}

Autism spectrum disorder (ASD) is a neurodevelopmental disorder characterized by deficits in social communication and social interaction and the presence of restricted, repetitive patterns of behavior, interests, or activities. Symptoms emerge during early development and can occur with or without intellectual and/or language impairment (Lai et al. 2014; APA 2013).

ASD can be associated with a wide range of concomitant challenging behaviors (Simonoff et al. 2008). In particular, moderate to severe symptoms of irritability (broadly defined to include tantrums, aggression, self-injurious behavior, and quickly changing moods) have been observed in about a quarter of subjects in various studies (Hill et al. 2014; Lecavalier 2006). These maladaptive behaviors can interfere with everyday activities, cause substantial caregiver stress, and may have a negative impact on long-term prognosis (Bradley et al. 2004; Eisenhower et al. 2005; Murphy et al. 2005; Lecavalier et al. 2006; Volkmar et al. 1999). In addition, aggressive or self-injurious behavior is associated with an increased risk 
of psychiatric hospitalization among children with ASD (Mandell 2008; Siegel et al. 2012).

The atypical antipsychotics risperidone and aripiprazole are currently the only medications approved by the United States Food and Drug Administration (FDA) for the treatment of irritability associated with ASD (Volkmar et al. 2014; Carroll et al. 2014; Politte et al. 2014). Thus, there is a need to identify additional efficacious agents, especially considering the safety and tolerability issues that may be associated with use of selected antipsychotics in children (Correll et al. 2009).

Lurasidone targets both the dopamine $\mathrm{D}_{2}$ and serotonin $5-\mathrm{HT}_{2 \mathrm{~A}}$ receptor systems with a pattern of high affinity binding that is comparable to what has been reported for risperidone and aripiprazole. The receptor binding profile of lurasidone demonstrates high affinity for $\mathrm{D}_{2}(\mathrm{Ki}, 1.68 \mathrm{nM}$; antagonist), 5- $\mathrm{HT}_{1 \mathrm{~A}}\left(\mathrm{Ki}, 6.74 \mathrm{nM}\right.$; partial agonist), 5- $\mathrm{HT}_{2 \mathrm{~A}}$ (Ki, $2.03 \mathrm{nM}$; antagonist), and $5-\mathrm{HT}_{7}$ receptors (Ki, $0.495 \mathrm{nM}$; antagonist); moderate affinity for noradrenergic $\alpha_{2 \mathrm{C}}(\mathrm{Ki}, 10.8 \mathrm{nM})$ and $\alpha_{2 \mathrm{~A}}(\mathrm{Ki}, 40.7 \mathrm{nM})$ receptors; and weak affinity for $5-\mathrm{HT}_{2 \mathrm{C}}$ receptors $(\mathrm{Ki}, 415 \mathrm{nM}$; Ishibashi et al. 2010). The receptor binding profile of lurasidone has more potent affinity for the $5-\mathrm{HT}_{1 \mathrm{~A}}$ receptor when compared with risperidone (Ishibashi et al. 2010). In addition, lurasidone, as well as risperidone, are full antagonists at the $\mathrm{D}_{2}$ receptor, while aripiprazole is a partial $\mathrm{D}_{2}$ agonist.

Lurasidone has been approved by the US FDA for the treatment of adults with schizophrenia (Nakamura et al. 2009; Meltzer et al. 2011; Nasrallah et al. 2013), and for the treatment of bipolar I depression in adults (Loebel et al. 2014a, b).

Here, we report the results of a randomized, doubleblind, placebo-controlled study to evaluate the efficacy, safety, and tolerability of lurasidone ( 20 or $60 \mathrm{mg} /$ day) compared with placebo in treating irritability in children and adolescents with autistic disorder.

\section{Methods}

This randomized, double-blind, fixed-dose, placebo-controlled study (ClinicalTrials.gov identifier: NCT01911442) was conducted at 40 sites in the US between September 2013 and November 2014. The study was approved by an Institutional Review Board at each investigational site and was conducted in accordance with the United States Code of Federal Regulations, the ethical principles that have their origin in the Declaration of Helsinki, and the International Conference on Harmonisation Good Clinical Practices guidelines. All parents and/or guardians provided written informed consent to participate; study subjects provided written informed assent when possible.

\section{Study Subjects}

The study enrolled outpatients, age 6-17 years, who met DSM-IV-TR criteria for a primary diagnosis of autistic disorder (APA 2000). The diagnosis was confirmed by the Autism Diagnostic Interview, Revised (ADI-R; Lord et al. 1994) administered at the Screening Visit by an experienced clinician who had previously completed a 2-day training course conducted by an ADI-R certified trainer. Enrollment required a score $\geq 18$ on the Irritability subscale of the Aberrant Behavior Checklist (ABC; Aman et al. 1985; Kaat et al. 2014), and a score $\geq 4$ (moderate-orgreater severity) on the Clinical Global Impression, Severity (CGI-S; Guy 1976).

Study subjects were excluded if they had a current diagnosis of bipolar disorder, schizophrenia, major depressive disorder, Fragile-X syndrome, or childhood disintegrative disorder as confirmed by the Mini International Neuropsychiatric Interview for children and adolescents (MINI-Kid; Sheehan et al. 2010) at Screening; or a confirmed genetic disorder associated with cognitive and/or behavioral disturbance or profound intellectual disability. Study subjects were also excluded if they had a history of seizures, unless they were seizure-free and off antiepileptic drugs for at least 6 months. Concurrent behavioral therapy for autism related symptoms or behaviors was permitted if it was stable for at least 4 weeks prior to Screening, and was consistent throughout the study.

\section{Study Design}

Study subjects who met study entry criteria were randomized, double-blind, in a 1:1:1 ratio (via an interactive voice/web response system) to receive fixed, once-daily doses of lurasidone ( 20 or $60 \mathrm{mg} /$ day), or matching placebo, administered in the evening with a meal, or within $30 \mathrm{~min}$ of eating. Study subjects randomized to the $60 \mathrm{mg}$ /day arm received lurasidone $20 \mathrm{mg}$ /day from Days 1-3, $40 \mathrm{mg}$ /day from Days 4-6, and $60 \mathrm{mg} /$ day from Day 7 to Week 6. If the subject was not able to tolerate the $60 \mathrm{mg} /$ day dose, a one-time dose reduction to $40 \mathrm{mg} /$ day was permitted (between Day 8 and 29); the $40 \mathrm{mg} / \mathrm{day}$ dose was then maintained for the remainder of the study.

Concomitant use of psychotropic medication was prohibited, with the exception of as-needed diphenhydramine ( $\leq 50 \mathrm{mg} /$ day) or melatonin ( $\leq 5 \mathrm{mg} /$ day) for insomnia, benztropine $(\leq 6 \mathrm{mg} /$ day $)$ for movement disorders, diphenhydramine ( $\leq 50 \mathrm{mg} /$ day) for acute extrapyramidal symptoms (EPS), or propranolol $(\leq 120 \mathrm{mg} /$ day $)$ for akathisia. 


\section{Assessments}

Efficacy assessments were obtained at baseline and weekly intervals. The primary efficacy measure was the caregiverrated Aberrant Behavior Checklist Irritability subscale score (ABC-I; Aman et al. 1985; Kaat et al. 2014). The $\mathrm{ABC}$ is a 58-item checklist that evaluates common problem behaviors in people with developmental disorders on a 4-point severity scale. Previous factor analyses (Aman et al. 1987; Newton and Sturmey 1988; Aman et al. 1995; Ono 1996; Brown et al. 2002) have validated its five subscales: (1) irritability and agitation, (2) social withdrawal and lethargy, (3) stereotypic behavior, (4) hyperactivity and non-compliance, and (5) inappropriate speech. The ABC-I subscale consist of 15 items and ranges from 0 (no problem behaviors) to a maximum of 45 . Secondary efficacy measures consisted of the other 4 subscales of the $\mathrm{ABC}$, the clinician-rated Clinical Global Impression, Severity (CGI-S) and Improvement (CGI-I) scales (Guy 1976), with instructions to assess the severity and degree of improvement in irritability associated with autism; and the Children's Yale-Brown Obsessive Compulsive Scales (CYBOCS) modified for pervasive developmental disorders (Scahill et al. 2006). The modified CY-BOCS is a clinician-rated, semistructured assessment that eliminates the obsessions checklist and severity scales of the CY-BOCS, while expanding the compulsions checklist to include repetitive behaviors more commonly seen in children with various developmental disorders. Caregivers of the study subject were administered the Caregiver Strain Questionnaire (CGSQ; Brannan et al. 1997), which measures the degree to which the child's condition is associated with disruption in family and community life, negative externalized emotions toward the child (anger, embarrassment), and negative internalized emotions (worry, guilt). A CGSQ global strain score is calculated by summing the three subscales and ranges from 3 to 15 .

\section{Safety and Tolerability Evaluations}

Safety and tolerability were assessed by the incidence and severity of adverse events during the study. In addition to potentially being reported as an adverse event, movement disorders were assessed in all study subjects by the Simpson-Angus Scale (SAS), the Abnormal Involuntary Movement Scale (AIMS) and the Barnes Akathisia Rating Scale (BARS; Guy 1976; Simpson and Angus 1970; Barnes 1989). Clinical chemistries (including selected metabolic parameters: glucose, cholesterol, HDL, LDL, triglycerides, hemoglobin A1c, insulin); hormonal measures (prolactin, thyrotropin and free thyroxine; testosterone [male] and serum human chorionic gonadotropin, follicle stimulating hormone, luteinizing hormone, and estradiol [female]; hematologies, urinalysis, and urine drug screen.

\section{Statistical Analysis}

The intent-to-treat population consisted of randomized study subjects who received at least one dose of study medication and had at least one post-baseline efficacy assessment. The primary (ABC Irritability subscale) and secondary efficacy endpoints were assessed using a mixed model for repeated measures (MMRM) analysis including treatment, visit, pooled center, baseline score, and a treatment-by-visit interaction term, using an unstructured covariance for within-patient correlation. For the CGI-I analysis, a similar MMRM model without baseline as a covariate was conducted.

Criteria for CGI-I response consisted of a score $\leq 2$ (much or very much improved) at endpoint; criteria for ABC-I response consisted of $\geq 25 \%$ improvement from Baseline to Endpoint. The categorical responder variable, the ABC Irritability subscale score, was analyzed with a logistic regression model with treatment, pooled center, and corresponding baseline score as covariate. The responder outcome, based on the CGI-I score at endpoint, was analyzed using the Cochran-Mantel-Haenszel (CMH) test controlling for treatment group, and pooled center. The primary efficacy measure corrected for multiple comparisons, however, since secondary efficacy measures were not corrected, these results should be viewed as descriptive.

The safety population included all study subjects who were randomized and received at least one dose of study medication. Descriptive statistics were used to analyze safety variables including adverse events (AEs), vital signs, weight, height, body mass index (BMI), ECG, and laboratory results. In addition, a nonparametric rank ANCOVA was used to analyze selected laboratory parameters. Change from baseline to endpoint in the Simpson-Angus Scale, the Abnormal Involuntary Movement Scale and the Barnes Akathisia Rating Scale scores were analyzed using an ANCOVA model with treatment, pooled center, and baseline as covariate. To account for normal growth in a pediatric population, percentiles and z-scores for height, weight and BMI were derived (CDC 2000). A BMI z-score change $<0.5$ is considered not clinically significant (Correll et al. 2009).

It was estimated, based on results from two previous trials with other atypical agents (McCracken et al. 2002; Owen et al. 2009), that a sample size of 40 study participants per group would provide at least $85 \%$ power to detect a difference from placebo as significant at the 0.05 level assuming a treatment difference of 7.0, and a common standard deviation of 11. An upward adjustment of $20 \%$ was made to compensate for expected attrition post- 
randomization, yielding a total sample of 150 study participants (50 per group).

\section{Results}

\section{Baseline Characteristics and Disposition}

A total of 150 study subjects were randomized to 6 weeks of double-blind treatment, of whom 149 received study drug (lurasidone or placebo; Fig. 1). Baseline demographic and clinical characteristics were similar across the three treatment groups (Table 1). The majority of study subjects were white $(77 \%)$, most were male $(82 \%) ; 72 \%$ were ages $6-12$ and $28 \%$ were ages $13-17$. The majority of study subjects reported previous psychotropic treatment, most commonly with an antipsychotic or a psychostimulant medication (Table 1).

The 6-week treatment completion rates were $76 \%$ for the placebo group, $88 \%$ for the lurasidone $20 \mathrm{mg} / \mathrm{day}$ group, and $92 \%$ for the lurasidone $60 \mathrm{mg} /$ day group (Fig. 1).

\section{Efficacy}

The least squares (LS) mean improvement in the $\mathrm{ABC}$ Irritability subscale score was not significantly different for the lurasidone $20 \mathrm{mg} /$ day group $(-8.8)$ and the $60 \mathrm{mg} /$ day group (-9.4) compared with placebo $(-7.5)$ at Week 6 (Fig. 2; Table 2). Improvement in the placebo group plateaued from Weeks 2-4, and then showed additional improvement from Weeks 4 to 6; Fig. 2).

On the CGI-Improvement score at Week 6, significant improvement was observed for the lurasidone $20 \mathrm{mg} /$ day group, and numerical improvement was observed for the $60 \mathrm{mg} /$ day group (Table 2). There was no significant difference at Week 6 for either dose of lurasidone compared with placebo on additional secondary efficacy measures, including other ABC subscales (hyperactivity, stereotypic behavior, inappropriate speech, lethargy/withdrawal), and on the CY-BOCS Compulsions scale, or the CGSQ Global Strain scale (Table 2). Since the secondary efficacy measures were not corrected for multiplicity, the results should be viewed as descriptive.

Week 6 responder rates, using the ABC-I criterion of $\geq 25 \%$ improvement from baseline, were 54.2 and $52.9 \%$, respectively, for lurasidone 20 and $60 \mathrm{mg} / \mathrm{day}$, and $57.1 \%$ for placebo (LOCF-endpoint); using a $\geq 50 \%$ improvement criterion, endpoint responder rates were 31.3 and $35.3 \%$, respectively, for lurasidone 20 and $60 \mathrm{mg} /$ day, and $22.4 \%$ for placebo. Figure 3 summarizes the distribution of CGI-I categories at baseline and week 6 .

In the $60 \mathrm{mg} /$ day lurasidone arm, a non-protocol specified dose reduction, from 60 to $40 \mathrm{mg} /$ day, occurred at week 5 in 17 study subjects (33\%). All 17 study subjects

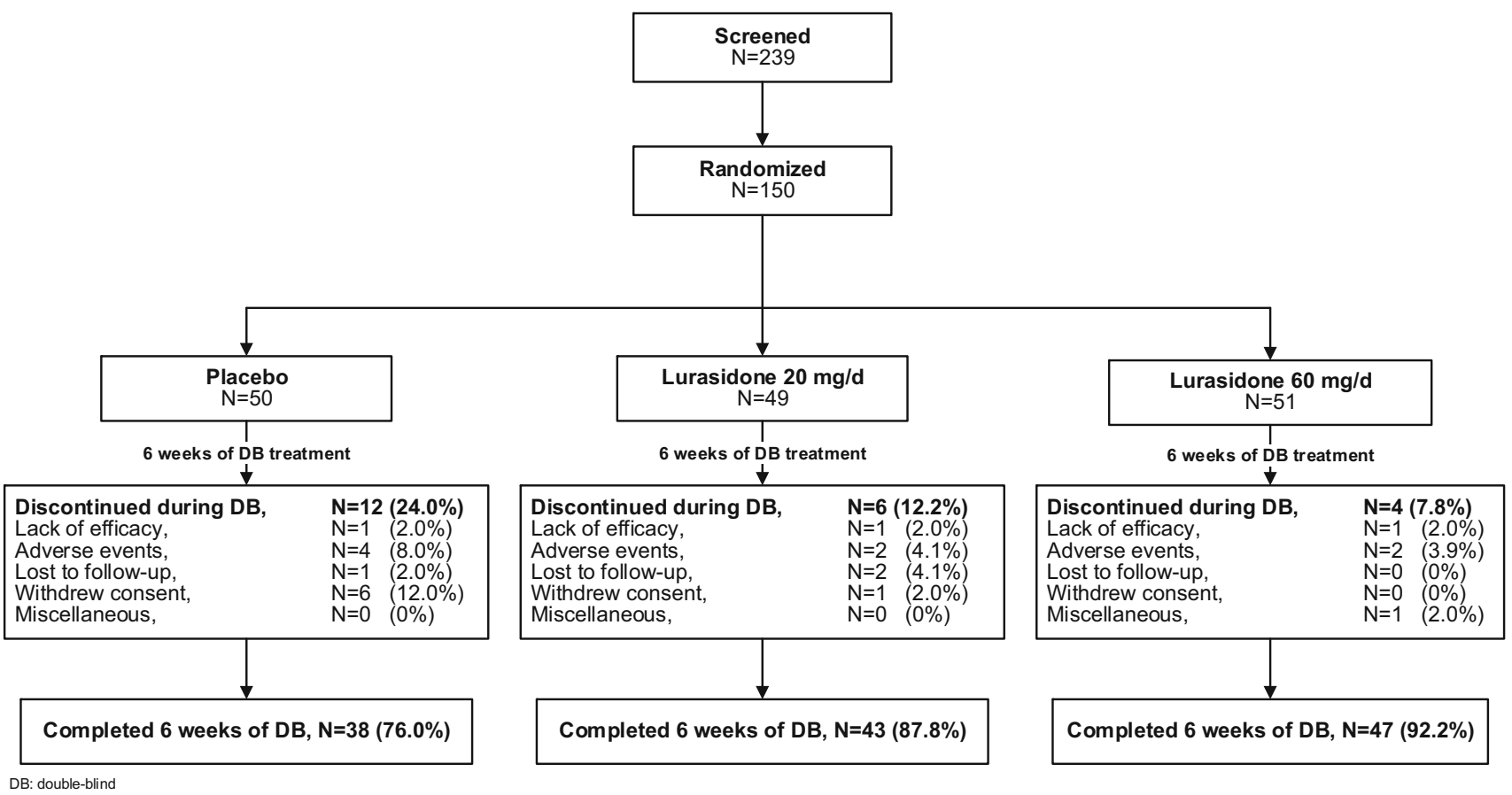

Fig. 1 Subject disposition 
Table 1 Baseline demographic and clinical characteristics (intent-to-treat population)

\begin{tabular}{|c|c|c|c|}
\hline & Placebo $(\mathrm{N}=49)$ & $\begin{array}{l}\text { Lurasidone } \\
20 \mathrm{mg} / \text { day }(\mathrm{N}=48)\end{array}$ & $\begin{array}{l}\text { Lurasidone } \\
60 \mathrm{mg} / \text { day }(\mathrm{N}=51)\end{array}$ \\
\hline Male, n (\%) & $40(81.6)$ & $38(79.2)$ & $43(84.3)$ \\
\hline \multicolumn{4}{|l|}{ Age, years } \\
\hline Mean (SD) & $11(3)$ & $10.5(3)$ & $10.5(3)$ \\
\hline $6-12, \mathrm{n}(\%)$ & $35(71.4)$ & $36(75.0)$ & $36(70.6)$ \\
\hline $13-17, \mathrm{n}(\%)$ & $14(28.6)$ & $12(25.0)$ & $15(29.4)$ \\
\hline \multicolumn{4}{|l|}{ Race, n (\%) } \\
\hline White & $42(86)$ & $34(71)$ & $38(74.5)$ \\
\hline Black & $5(10)$ & $10(21)$ & $9(17.6)$ \\
\hline Other & $2(4)$ & $4(8)$ & $4(7.8)$ \\
\hline \multicolumn{4}{|l|}{ Weight $(\mathrm{kg})$} \\
\hline Mean (SD) & $43(14)$ & $42(17)$ & $44(17)$ \\
\hline Percentile, mean (SD) & $59(27)$ & $57(30)$ & $67(27)$ \\
\hline \multicolumn{4}{|l|}{ BMI, $\mathrm{kg} / \mathrm{m}^{2}$} \\
\hline Mean (SD) & $19.2(3.2)$ & $18.8(3.5)$ & $19.2(3.3)$ \\
\hline Percentile, mean (SD) & $61(30)$ & $59(29)$ & $64(29)$ \\
\hline \multicolumn{4}{|c|}{ Prior psychotropic medication, $\mathrm{n}(\%)$} \\
\hline Any antipsychotic & $19(38.8)$ & $17(35.4)$ & $16(31.4)$ \\
\hline Any psychostimulant & $18(36.7)$ & $11(22.9)$ & $16(31.4)$ \\
\hline Any antidepressant & $6(12.2)$ & $8(16.7)$ & $5(9.8)$ \\
\hline \multicolumn{4}{|l|}{ Baseline scores, mean $(\mathrm{SD})^{\mathrm{a}}$} \\
\hline $\mathrm{ABC}$ irritability/agitation & $29(7)$ & $28(6)$ & $27(6)$ \\
\hline CGI-severity & $5.0(0.8)$ & $4.9(0.8)$ & $4.7(0.8)$ \\
\hline
\end{tabular}

17 Subjects in the $60 \mathrm{mg} /$ day dosing group received a non-protocol specified dose reduction to $40 \mathrm{mg} /$ day at week 5

$A B C$ aberrant behavior checklist, $B M I$ body mass index, $C G I$ clinical global impression, $C Y$ - $B O C S$ Children's Yale-Brown Obsessive-Compulsive Scale

${ }^{\text {a }}$ Intent-to-treat population

Fig. 2 Mean change from baseline in the ABC irritability subscale score (ITT population)

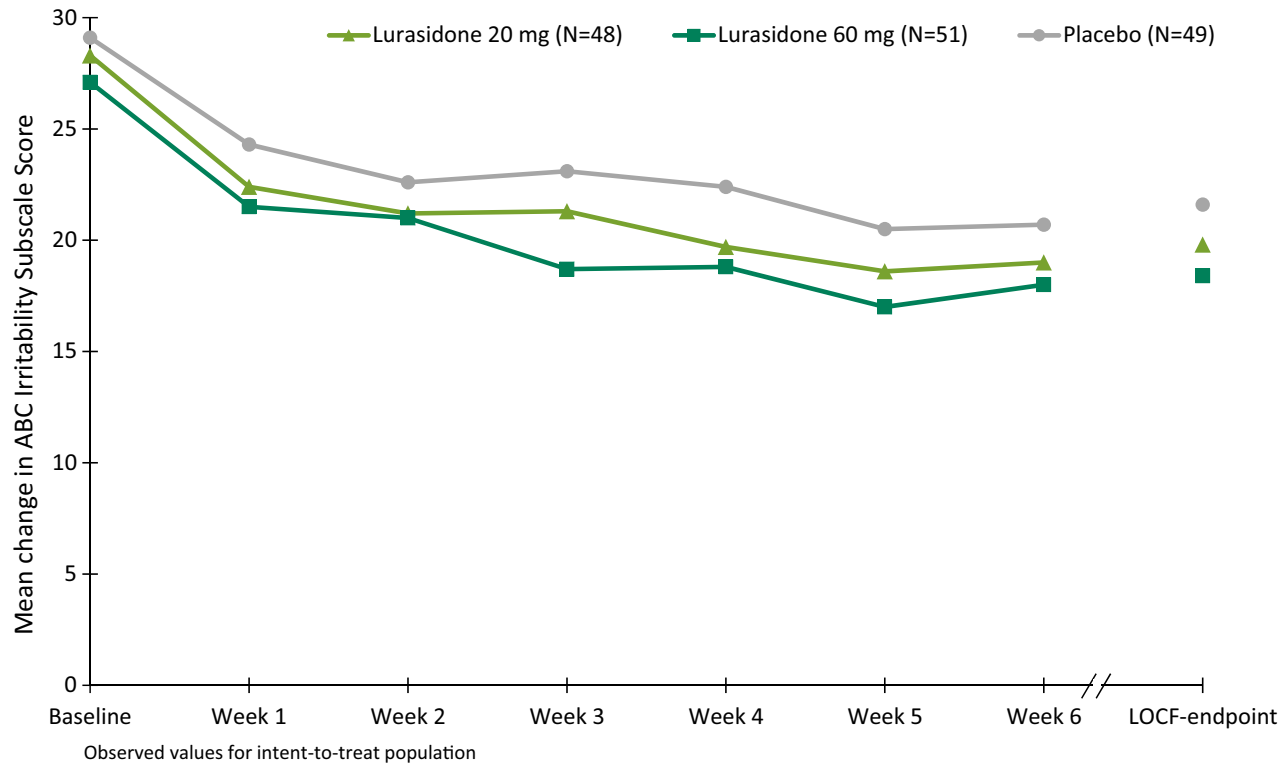


Table 2 Efficacy endpoints: change at week 6 (ITT population; MMRM)

\begin{tabular}{|c|c|c|c|c|c|c|c|}
\hline & \multirow{2}{*}{$\begin{array}{l}\text { Placebo } \\
(\mathrm{N}=49)\end{array}$} & \multirow{2}{*}{$\begin{array}{l}\text { Lurasidone } \\
20 \mathrm{mg} / \text { day } \\
(\mathrm{N}=48)\end{array}$} & \multirow{2}{*}{$\begin{array}{l}\text { Lurasidone } \\
60 \mathrm{mg} / \mathrm{day} \\
(\mathrm{N}=51)\end{array}$} & \multicolumn{4}{|l|}{ Treatment Difference } \\
\hline & & & & $\begin{array}{l}\text { LUR-20 versus } \\
\text { PBO }(95 \% \mathrm{CI})\end{array}$ & $p$ & $\begin{array}{l}\text { LUR-60 versus } \\
\text { PBO }(95 \% \text { CI })\end{array}$ & $p$ \\
\hline \multicolumn{8}{|l|}{$\mathrm{ABC}$ irritability/agitation } \\
\hline Baseline mean (SD) & $29.1(6.9)$ & $28.3(5.9)$ & $27.1(5.7)$ & $-1.3(-5.6,3.0)$ & 0.55 & $-1.9(-6.1,2.2)$ & 0.36 \\
\hline LS mean change (SE) & $-7.5(1.5)$ & $-8.8(1.5)$ & $-9.4(1.4)$ & & & & \\
\hline \multicolumn{8}{|l|}{ ABC Hyperactivity, baseline } \\
\hline Baseline mean $(\mathrm{SD})$ & $34.0(9.2)$ & $32.5(8.7)$ & $31.2(11.3)$ & $-2.5(-6.8,1.7)$ & 0.24 & $+0.5(-3.6,4.6)$ & 0.81 \\
\hline LS mean change (SE) & $-7.1(1.5)$ & $-9.7(1.5)$ & $-6.6(1.4)$ & & & & \\
\hline \multicolumn{8}{|l|}{$\mathrm{ABC}$ stereotypic behavior } \\
\hline Baseline mean (SD) & $9.3(6.3)$ & $8.9(5.2)$ & $8.2(5.1)$ & $-1.1(-3.0,0.8)$ & 0.26 & $+0.9(-0.9,2.8)$ & 0.31 \\
\hline LS mean change (SE) & $-2.6(0.7)$ & $-3.7(0.7)$ & $-1.6(0.6)$ & & & & \\
\hline \multicolumn{8}{|l|}{$\mathrm{ABC}$ inappropriate speech } \\
\hline Baseline mean (SD) & $7.2(3.3)$ & $6.8(3.3)$ & $6.5(3.3)$ & $+0.2(-1.0,1.4)$ & 0.76 & $+0.1(-1.1,1.3)$ & 0.87 \\
\hline LS mean change (SE) & $-1.6(0.4)$ & $-1.4(0.4)$ & $-1.5(0.4)$ & & & & \\
\hline \multicolumn{8}{|l|}{$\mathrm{ABC}$ lethargy/withdrawal } \\
\hline Baseline mean $(\mathrm{SD})$ & $18.7(10.8)$ & $15.2(9.8)$ & $17.4(10.1)$ & $-0.3(-3.4,2.8)$ & 0.86 & $-0.9(-3.9,2.1)$ & 0.55 \\
\hline LS mean change (SE) & $-6.5(1.1)$ & $-6.8(1.1)$ & $-7.4(1.0)$ & & & & \\
\hline \multicolumn{8}{|l|}{ CGI-severity } \\
\hline Baseline mean $(\mathrm{SD})$ & $5.0(0.8)$ & $4.9(0.8)$ & $4.7(0.8)$ & $-0.3(-0.8,0.2)$ & 0.18 & $-0.3(-0.8,0.2)$ & 0.24 \\
\hline LS mean change (SE) & $-0.7(0.2)$ & $-1.1(0.2)$ & $-1.0(0.2)$ & & & & \\
\hline \multicolumn{8}{|l|}{ CGI-improvement $^{\mathrm{a}}$} \\
\hline LS mean at week $6(\mathrm{SE})$ & $3.4(0.2)$ & $2.8(0.2)$ & $3.1(0.2)$ & $-0.6(-1.1,-0.0)$ & 0.035 & $-0.3(-0.8,0.2)$ & 0.27 \\
\hline \multicolumn{8}{|l|}{ CY-BOCS Compulsions } \\
\hline Baseline mean (SD) & $12.9(4.6)$ & $10.7(5.7)$ & $10.6(5.7)$ & $0.2(-1.2,1.5)$ & 0.82 & $0.2(-1.1,1.5)$ & 0.73 \\
\hline LS mean change (SE) & $-1.2(0.5)$ & $-1.0(0.5)$ & $-1.0(0.4)$ & & & & \\
\hline \multicolumn{8}{|l|}{ CGSQ global strain, baseline } \\
\hline Baseline mean (SD) & $10.0(1.8)$ & $9.3(2.5)$ & $9.5(2.0)$ & $-0.1(-1.0,0.7)$ & 0.75 & $-0.3(-1.1,0.5)$ & 0.45 \\
\hline LS mean change (SE) & $-1.4(0.3)$ & $-1.5(0.3)$ & $-1.7(0.3)$ & & & & \\
\hline
\end{tabular}

$M M R M$ mixed model for repeated measures, $A B C$ aberrant behavior checklist, $C G I$ clinical global impression, $C Y$-BOCS Children's Yale-Brown Obsessive-Compulsive Scale, CGSQ caregiver strain questionnaire, $C I$ confidence interval, $L U R$ lurasidone, $P B O$ placebo

${ }^{\text {a }}$ Total sccore (not change score)

Fig. 3 CGI-improvement category at LOCF-endpoint (ITT population)

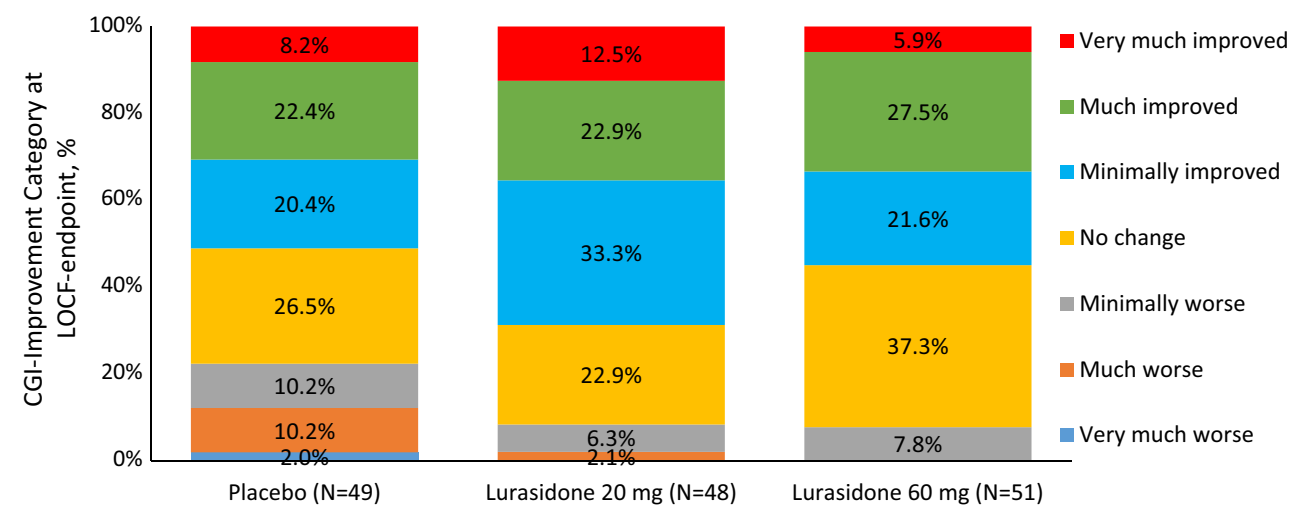

completed the final week of the study. Consistent with the intent to treat analysis plan, these study subjects were analyzed with the $60 \mathrm{mg} /$ day dosage group to which they had been randomized. Results at week 6 on the primary efficacy outcome were similar for the dose reduction and non-dose reduction groups. 


\section{Safety}

Treatment-emergent adverse events (TEAEs) are summarized in Table 3A. The percentage of study subjects with TEAEs was 71 and $75 \%$, respectively, in the 20 and $60 \mathrm{mg}$ /day lurasidone groups, and $57 \%$ in the placebo group. Rates of adverse events were somewhat higher for both the 20 and $60 \mathrm{mg} /$ day groups, respectively in 6-12 years old study subjects $(60.0,75.0 \%)$, and in 13-17 years old study subjects $(50.0,67.9 \%)$. Adverse events leading to study discontinuation were nausea and irritability (one each in the $20 \mathrm{mg}$ /day group), vomiting and suicidal ideation (one each in the $60 \mathrm{mg} /$ day group), and irritability, decreased appetite, disturbance in attention, psychomotor hyperactivity, and affective lability (one each in the placebo group). The majority of adverse events were rated as mild or moderate; the incidence of events rated as "severe" was $12.2 \%$ in the lurasidone $20 \mathrm{mg}$ /day group, $2.0 \%$ in the lurasidone $60 \mathrm{mg} /$ day group, and $10.2 \%$ in the placebo group. There were 5 serious TEAEs (SAEs), 3 on the $20 \mathrm{mg} /$ day dose of lurasidone ( $\operatorname{rrm}$ fractures, $\mathrm{n}=2$; increased irritability, $\mathrm{n}=1$ ), and 2 on the $60 \mathrm{mg} /$ day dose of lurasidone (arm fracture, $\mathrm{n}=1$; appendicitis, $\mathrm{n}=1$ ).

Treatment with lurasidone (20 and $60 \mathrm{mg} / \mathrm{day}$ vs. placebo) was associated with small mean changes at the Week 6 endpoint in the BARS total score $(+0.08$ and -0.12 vs. $+0.00)$ and the SAS 10-item mean score $(-0.01$ and -0.05 vs. -0.01 ); no shift from normal to abnormal in the AIMS total score were observed in either of the two lurasidone groups, while one study subject shifted from normal to

Table 3 Tolerability and safety of lurasidone treatment (safety population)

\begin{tabular}{|c|c|c|c|}
\hline & Placebo $(\mathrm{N}=49)$ & $\begin{array}{l}\text { Lurasidone } \\
20 \mathrm{mg} / \text { day }(\mathrm{N}=49)\end{array}$ & $\begin{array}{l}\text { Lurasidone } \\
60 \mathrm{mg} / \text { day }(\mathrm{N}=51)\end{array}$ \\
\hline \multicolumn{4}{|c|}{ A. Treatment-emergent adverse events (incidence $\geq 5 \%{ }^{a}$ ), $n(\%)$} \\
\hline Any adverse event & $28(57)$ & $35(71)$ & $38(75)$ \\
\hline Vomiting & $2(4)$ & $4(8)$ & $14(28)$ \\
\hline Somnolence & $2(4)$ & $3(6)$ & $9(18)$ \\
\hline Nasopharyngitis & $0(0)$ & $5(10)$ & $3(6)$ \\
\hline Akathisia & $0(0)$ & $3(6)$ & $3(6)$ \\
\hline Fatigue & $1(2)$ & $1(2)$ & $4(8)$ \\
\hline Weight increased & $1(2)$ & $1(2)$ & $4(8)$ \\
\hline Cough & $2(4)$ & $2(4)$ & $3(6)$ \\
\hline Sedation & $1(2)$ & $3(6)$ & $1(2)$ \\
\hline Constipation & $1(2)$ & $0(0)$ & $3(6)$ \\
\hline Nausea & $0(0)$ & $2(4)$ & $3(6)$ \\
\hline \multicolumn{4}{|c|}{ B. Change in weight, BMI, and fasting laboratory parameters (week $6^{b}$ ) } \\
\hline \multicolumn{4}{|l|}{ Weight, kg } \\
\hline LS mean (SE) change & $+0.4(0.2)$ & $+0.5(0.2)$ & $+1.2(0.2)^{\mathrm{d}}$ \\
\hline Mean (SD) change in percentile & $-0.9(6.6)$ & $+0.8(5.4)$ & $+2.7(6.5)$ \\
\hline LS mean (SE) z-score change & $-0.02(0.03)$ & $+0.02(0.03)$ & $+0.09(0.03)$ \\
\hline \multicolumn{4}{|l|}{ BMI $\left(\mathrm{kg} / \mathrm{m}^{2}\right)$} \\
\hline LS mean (SE) change & $-0.0(0.1)$ & $-0.04(0.1)$ & $+0.4(0.1)$ \\
\hline Mean (SD) change in percentile & $-1.1(7.6)$ & $+0.3(6.5)$ & $+3.3(9.5)$ \\
\hline LS mean (SE) z-score change & $-0.02(0.04)$ & $-0.02(0.04)$ & $+0.1(0.04)$ \\
\hline Waist circumference, $\mathrm{cm}$, mean (SD) change & $+0.5(3.0)$ & $+0.2(1.6)$ & $+1.1(2.6)$ \\
\hline Cholesterol $(\mathrm{mg} / \mathrm{dL} \text {, median change })^{\mathrm{c}}$ & -5.0 & +6.0 & +7.5 \\
\hline 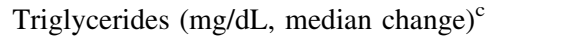 & -4.0 & +1.0 & +15.0 \\
\hline Glucose $(\mathrm{mg} / \mathrm{dL} \text {, median change })^{\mathrm{c}}$ & -5.0 & -1.0 & -1.0 \\
\hline HbA1c (\%, mean (SD) change) & $+0.0(0.3)$ & $+0.1(0.2)$ & $+0.1(0.4)$ \\
\hline Prolactin (ng/mL, mean (SD) change) & $-0.1(5.9)$ & $-0.2(9.0)$ & $+2.3(13.9)$ \\
\hline
\end{tabular}

$B M I$ body mass index, $H b A l c$ glycosylated hemoglobin

${ }^{a}$ Adverse events shown where incidence on lurasidone $>$ placebo

b Endpoint data, except for weight and BMI, which were analyzed by MMRM

${ }^{c}$ Fasting subjects: placebo $(\mathrm{n}=36)$; lurasidone $20 \mathrm{mg} /$ day $(\mathrm{n}=37)$; lurasidone $60 \mathrm{mg} /$ day $(\mathrm{n}=45)$

${ }^{\mathrm{d}} p$ value (vs. placebo): 0.015 
abnormal in the placebo group. The only EPS symptom reported by more than one study subject in a treatment group was akathisia (Table 3A). No concomitant antiParkinsonian medication or benzodiazepines were used by study subjects in either of the three treatment groups.

Increased weight was observed in all three treatment groups at Week 6 (Table 3B). The increased weight was similar for lurasidone $20 \mathrm{mg} /$ day compared with placebo, but a greater increase was noted for the lurasidone $60 \mathrm{mg} /$ day group. The mean z-score change in both weight and BMI were similar for lurasidone $20 \mathrm{mg} /$ day and $60 \mathrm{mg} /$ day versus placebo $(-0.02$ and +0.1 vs. -0.02$)$. Six weeks of treatment with lurasidone was associated with minimal changes in laboratory parameters compared with placebo, with the exception of an increase for the lurasidone $60 \mathrm{mg} /$ day group versus placebo in triglycerides (median change, +13.0 vs. $-4.0 \mathrm{mg} / \mathrm{dL}$ ) and cholesterol (median change, +8.0 vs. $-5.0 \mathrm{mg} / \mathrm{dL}$ ). No clinically meaningful effect on vital signs or ECG parameters were observed; changes at Week 6 in QTcF were $+0.3 \mathrm{~ms}$, $-1.1 \mathrm{~ms}$, and $+3.2 \mathrm{~ms}$, respectively, for the placebo, lurasidone 20, and $60 \mathrm{mg} / \mathrm{day}$ groups. No study subjects treated with lurasidone had clinically significant ECG abnormalities.

\section{Discussion}

In this randomized, double-blind, fixed-dose (20, $60 \mathrm{mg} /$ day), 6-week study, lurasidone did not significantly differentiate from placebo on the primary endpoint, change in the ABC Irritability subscale. Significantly greater improvement was observed at endpoint on the CGI-I scale for the lurasidone $20 \mathrm{mg}$ /day group compared with the placebo group. However, no significant difference was observed for either dose of lurasidone compared with placebo on other secondary efficacy measures at either dose.

The precise pathophysiology of irritable, aggressive and/ or self-injurious behavior in autistic disorder has not been determined. Abnormal serotonergic and/or dopaminergic neurotransmission has been hypothesized to be related to this constellation of behaviors, which suggests a potential therapeutic role for atypical antipsychotics (Lesch and Merschdorf 2000; Moore et al. 2002; Siever 2008; Seo et al. 2008; Callesen et al. 2013; Duke et al. 2013; Kolevzon et al. 2014).

Risperidone and aripiprazole have demonstrated efficacy in the treatment of irritability associated with autistic disorder (McCracken et al. 2002; Owen et al. 2009; Marcus et al. 2009). Risperidone, aripiprazole, and lurasidone target both the dopamine $\mathrm{D}_{2}$ and serotonin (5-HT) receptor systems with a comparable pattern of high affinity binding
(Ishibashi et al. 2010; Gründer et al. 2006). Furthermore, experience in clinical practice suggests that lurasidone may be useful for the treatment of irritability associated with autistic disorder (Millard et al. 2014). However, the results of the current study did not confirm the efficacy of lurasidone in this population.

The reasons for the negative results of the current study are uncertain. Differences in study populations between this study and the aripiprazole and risperidone studies do not appear to account for the negative findings. Baseline characteristics of the current study population were similar to previously reported positive short-term trials of risperidone (McCracken et al. 2002; McDougle et al. 2005) and aripiprazole (Owen et al. 2009; Marcus et al. 2009), with one notable exception: a somewhat higher proportion of study subjects in the current trial reported a history of prior treatment with antipsychotics (35\%) compared with clinical trials of risperidone (6\%) and aripiprazole (21\%). It is also possible that subtle differences in the pharmacology of lurasidone compared with risperidone and aripiprazole may account for the lack of observed efficacy in the current trial.

Based on the level of improvement observed on placebo, the current study population did not appear to be notably treatment-resistant. Week 6 improvement in the ABC-I on placebo in the current study $(-7.5)$ was larger than has been reported for risperidone $(-3.5$; McCracken et al. 2002) and for one of the aripiprazole trials ( -5.0 ; Marcus et al. 2009) but not for the other aripiprazole trial (-8.4; Owen et al. 2009). Finally, it is possible that the lack of flexible dosing might have reduced the ability to detect an efficacy signal.

Discontinuations due to adverse events were lower in both lurasidone groups compared with placebo. Treatmentemergent adverse events were typically mild-to-moderate in severity. Only vomiting and somnolence showed apparent substantial dose-related increases in event rates. The $20 \mathrm{mg} /$ day dose of lurasidone was generally similar to placebo in its effects on weight, metabolic parameters, and prolactin. The $60 \mathrm{mg} /$ day dose of lurasidone was associated with increased effects on weight and lipids (but not glycemic indices), and prolactin. As with all study participants, especially younger ones, clinicians should be mindful of potential weight and metabolic changes that can occur during treatment with an atypical antipsychotic, though different antipsychotics have demonstrated different metabolic risk profiles (Correll et al. 2015; Galling and Correll 2015).

Several potential study limitations should be noted. First is the absence of an active (risperidone or aripiprazole) control group. Inclusion of an active control group is the only reliable method for determining whether a treatmentresponsive sample has been recruited, or whether the assay 
was defective, and the study was a failed trial rather than a negative trial. Second, the study design did not include a single-blind, placebo run-in period, which may have served to reduce the placebo response rate. Third, no formal cognitive assessment of intellectual functioning was obtained. Patients with profound intellectual disability, based on investigator judgment, were excluded from study entry, however, the contribution of baseline intellectual functioning to study outcome could not be ascertained. Finally it should be noted that relatively few placebocontrolled clinical trials have been conducted in irritability associated with autistic disorder. Therefore, our confidence in the reliability and validity of the outcome measures, and the sample size required to detect a treatment effect are not nearly as well established as they are for other disorders.

In conclusion, in this randomized, placebo-controlled 6-week study, lurasidone did not demonstrate statistically significant efficacy for the treatment of irritability associated with autistic disorder. The safety profile of lurasidone was consistent with the safety profile in adults, with the exception of some weight gain seen at the higher dose in this pediatric population.

\section{Clinical Significance}

In this randomized, placebo-controlled 6-week study, treatment with a fixed dose of lurasidone ( 20 or $60 \mathrm{mg} /$ day) was not found to be significantly superior to placebo in reducing moderate-to-severe irritability in children and adolescents with a diagnosis of autistic disorder. Although some individual study subjects had meaningful improvements in symptoms, the lack of statistical significance on the primary outcome measure compared with placebo is in contrast to significant efficacy previously reported for two other atypical antipsychotics, risperidone and aripiprazole, both of which are FDA approved for this use.

\footnotetext{
Acknowledgments The original clinical research was sponsored by Sunovion Pharmaceuticals Inc. The sponsor was involved in the design, collection, and analysis of the data. The authors thank all the children and caregivers who participated in this study, as well as the investigators at each study site: Dr. Sarah D. Atkinson, Finger Lakes Clinical Research, Rochester, NY; Dr. Mark DiBuono, Richmond Behavioral Associates, Staten Island, NY; Dr. Robert L. Findling, Johns Hopkins Hospital, Baltimore, MD; Dr. Salma Malik, Institute of Living/Hartford Hospital, Hartford, CT; Dr. Kashinath G. Yadalam, Lake Charles Clinical Trials, Lake Charles, LA; Dr. Nelson M. Handal, Harmonex Neuroscience Research, Inc. Dothan, AL; Dr. John Calcagno, Cyn3rgy Research, Gresham, OR; Dr. Ann C. Childress, Center for Psychiatry and Behavioral Medicine, Inc., Las Vegas, NV; Dr. Paul E. Glaser, University of Kentucky Department of Psychiatry Research, Lexington, KY; Dr. Robert Lee Hendren, University of California, San Francisco, CA; Dr. Eric Hollander, Montefiore Medical Center, Albert Einstein College of Medicine, Bronx, NY; Dr. Willis Holloway, Jr., Cutting Edge Research Group,
}

Oklahoma City, OK; Joanne L. Northcutt, Florida Clinical Research Center, LLC, Maitland, FL; Dr. Miguel A. Perez, Palm Springs Research Institute, Hialeah, FL; Dr. Robert Bond Molpus, Clinical Neuroscience Solutions, Inc., Orlando, FL; Dr. Adly Thebaud, Medical Research Group of Central Florida, Sanford, FL; Dr. Marshall B. Lucas, Family Psychiatry of the Woodlands, The Woodlands, TX; Dr. Jose T. Zaglul, Florida Clinical Research Center, LLC, Bradenton, FL; Sharon B. Wigal, Newport Beach Clinical Research Associates, Inc., Newport Beach, CA; Dr. Michael Greenbaum, Capstone Clinical Research, Libertyville, IL; Dr. Nandita Joshi, Clinical Neuroscience Solutions Inc., Jacksonville, FL; Dr. Raun David Melmed, The Southwest Autism Research and Resource Center (SARRC), Phoenix, AZ; Dr. Riaz A. Baber, Baber Research Group, Inc. Naperville, IL; Dr. Linmarie Sikich, UNC Chapel Hill Department of Psychiatry, Chapel Hill, NC; Dr. Syed Jamal Mustafa, Pacific Institute of Medical Sciences, Bothell, WA; Dr. Anita Sherry Kablinger, Carillon Clinic, Roanoke, VA; Dr. Ramon Solhkhah, Jersey Shore University Medical Center, Neptune, NJ; Dr. Samantha Bostrom, Ericksen Research and Development, Clinton, UT; Dr. Nora K. McNamara, Discovery and Wellness Center for Children University Hospitals Case Medical Center Division of Child and Adolescent Psychiatry, Cleveland, OH; Dr. Elias H. Sarkis, Sarkis Clinical Trials, Gainesville, FL; Dr. Matthews N. Brams, Bayou City Research, Ltd., Houston, TX; Dr. Steven Gerald Lopez, Carolina Clinical Trials, Inc., Charleston, SC; Dr. Tanya Murphy, University of South Florida Rothman Center of Neuropsychiatry, St. Petersburg, FL; Dr. Reid Robison, Lifetree Clinical Research, Salt Lake City, UT; Dr. Daniel Fallon, University of South Florida, Department of Psychiatry and Behavioral Neurosciences, Tampa, FL; Jeffrey Lewine, Lovlac Scientific Resources, Inc., Albuquerque, NM; Dr. Vishal Madaan, UVA Child and Family Psychiatry Clinic, Charlottesville, VA; Dr. Yvette M. Janvier, Children's Specialized Hospital, Toms River, NJ; Jill Hollway, The Ohio State University Nisonger Center, Columbus, OH; Keith E. Saylor, Neuro Science, Inc., Herndon, VA; Dr. Valerie K. Arnold, Clinical Neuroscience Solutions, Inc., Memphis, TN; Dr. Shivkumar Hatti, Suburban Research Associates, Media, PA; Dr. Ashraf M. Atalla, Attalla Consultants, LLC dba Institute for Behavioral Medicine, Smyrna, GA; Dr. Richard Jackson, Neurobehavior Medicine Group, Bloomfield Hills, MI; Dr. Gagan Joshi, Massachusetts General Hospital, Boston, MA; Dr. Naveena Hemanth, NeuroScientific Insights, Rockville, MD; Dr. David Bruce Waslick, Baystate Medical Center, Springfield, MA. The authors also thank Edward Schweizer, MD, of Paladin Consulting Group, who provided editorial assistance for this manuscript, under the direction of the authors, which was funded by Sunovion Pharmaceuticals Inc.

Author Contributions AL, MB, RSG, LD, and RLF contributed to the design of the study. AL, MB, RSG, RS, DH, LD, RM, RFL were involved in the collection and/or interpretation of the data. LD performed the statistical analysis. All authors participated in the critical revision of the current paper, and approved the final draft.

\section{Compliance with Ethical Standards}

Conflict of interest Drs. Loebel, Goldman, Silva, Hernandez, Mankoski, and Deng are employees of Sunovion Pharmaceuticals Inc. Dr. Brams has been a speaker, consultant, and served on advisory boards for Novartis Pharmaceuticals Corp and Shire; and has received grant-research support from Novartis Pharmaceuticals Corp, Shire, and Eli Lilly. Dr. Findling receives or has received research support, acted as a consultant and/or served on a speaker's bureau for Alcobra, American Academy of Child \& Adolescent Psychiatry, American Physician Institute, American Psychiatric Press, AstraZeneca, Bracket, Bristol-Myers Squibb, CogCubed, Cognition Group, Coronado Biosciences, Dana Foundation, Elsevier, Forest, GlaxoSmithKline, Guilford Press, Johns Hopkins University Press, 
Johnson and Johnson, Jubilant Clinsys, KemPharm, Lilly, Lundbeck, Merck, NIH, Neurim, Novartis, Noven, Otsuka, Oxford University Press, Pfizer, Physicians Postgraduate Press, Purdue, Rhodes Pharmaceuticals, Roche, Sage, Shire, Sunovion, Supernus Pharmaceuticals, Transcept Pharmaceuticals, Validus, and WebMD.

Open Access This article is distributed under the terms of the Creative Commons Attribution 4.0 International License (http://crea tivecommons.org/licenses/by/4.0/), which permits unrestricted use, distribution, and reproduction in any medium, provided you give appropriate credit to the original author(s) and the source, provide a link to the Creative Commons license, and indicate if changes were made.

\section{References}

Aman, M. G., Burrow, W. H., \& Wolford, P. L. (1995). The Aberrant Behavior Checklist-Community: Factor validity and effect of subject variables for adults in group homes. American Journal of Mental Retardation, 100, 283-292.

Aman, M. G., Richmond, G., Stewart, A. W., Bell, J. C., \& Kissel, R. C. (1987). The aberrant behavior checklist: Factor structure and the effect of subject variables in American and New Zealand facilities. American Journal of Mental Deficiency, 91, 570-578.

Aman, M. G., Singh, N. N., Stewart, A. W., \& Field, C. J. (1985). The aberrant behavior checklist: A behavior rating scale for the assessment of treatment effects. American Journal of Mental Deficiency, 89, 485-491.

American Psychiatric Association. (2000). Diagnostic and statistical manual of mental disorders, 4th Edition, text revision (DSM-IVTR). Arlington: American Psychiatric Publishing.

American Psychiatric Association. (2013). Diagnostic and statistical manual of mental disorders: DSM-5. Washington, DC: American Psychiatric Association.

Barnes, T. R. E. (1989). A rating scale for drug-induced akathisia. British Journal of Psychiatry, 154, 672-676.

Bradley, E. A., Summers, J. A., Wood, H. L., \& Bryson, S. E. (2004). Comparing rates of psychiatric and behavior disorders in adolescents and young adults with severe intellectual disability with and without autism. Journal of Autism and Developmental Disorders, 34, 151-161.

Brannan, A. M., Heflinger, C. A., \& Bickman, L. (1997). The caregiver strain questionnaire: Measuring the impact on the family of living with a child with serious emotional disturbance. Journal of Emotional and Behavioral Disorders, 5, 212-222.

Brown, E. C., Aman, M. G., \& Havercamp, S. M. (2002). Factor analysis and norms for parent ratings on the Aberrant Behavior Checklist-Community for young people in special education. Research in Developmental Disabilities, 23, 45-60.

Callesen, M. B., Scheel-Krüger, J., Kringelbach, M. L., \& Møller, A. (2013). A systematic review of impulse control disorders in Parkinson's disease. Journal of Parkinsons Disease, 3, 105-138.

Carroll, D., Hallett, V., \& McDougle, C. J. (2014). Examination of aggression and self-injury in children with autism spectrum disorders and serious behavioral problems. Child and Adolescent Psychiatric Clinics of North America, 23, 57-72.

Centers for Disease Control and Prevention. (2000). Growth charts for the United States, 2000. Accessed on the web on May 6, 2015. http://www.cdc.gov/growthcharts/cdc_charts.htm

Correll, C. U., Joffe, B. I., Rosen, L. M., Sullivan, T. B., \& Joffe, R. T. (2015). Cardiovascular and cerebrovascular risk factors and events associated with second-generation antipsychotic compared to antidepressant use in a non-elderly adult sample: results from a claims-based inception cohort study. World Psychiatry, 14, 56-63.
Correll, C. U., Manu, P., Olshanskiy, V., Napolitano, B., Kane, J. M., \& Malhotra, A. K. (2009). Cardiometabolic risk of secondgeneration antipsychotic medications during first-time use in children and adolescents. JAMA, 302, 1765-1773.

Duke, A. A., Bègue, L., Bell, R., \& Eisenlohr-Moul, T. (2013). Revisiting the serotonin-aggression relation in humans: a metaanalysis. Psychological Bulletin, 139, 1148-1172.

Eisenhower, A. S., Baker, B. L., \& Blacher, J. (2005). Preschool children with intellectual disability: syndrome specificity, behaviour problems, and maternal well-being. Journal of Intellectual Disability Research, 49, 657-671.

Galling, B., \& Correll, C. U. (2015). Do antipsychotics increase diabetes risk in children and adolescents? Expert Opinion on Drug Safety, 14, 219-241.

Gründer, G., Kungel, M., Ebrecht, M., Göröcs, T., \& Modell, S. (2006). Aripiprazole: Pharmacodynamics of a dopamine partial agonist for the treatment of schizophrenia. Pharmacopsychiatry, 39(Suppl 1), S21-S25.

Guy, W. (1976). EDCEU assessment manual for psychopharmacology -Revised (DHEW Publ No ADM 76-338). Rockville, MD, U.S. Department of Health, Education, and Welfare, Public Health Service, Alcohol, Drug Abuse, and Mental Health Administration, NIMH Psychopharmacology Research Branch, Division of Extramural Research Programs, pp. 534-537.

Hill, A. P., Zuckerman, K. E., Hagen, A. D., Kriz, D. J., Duvall, S. W., van Santen, J., et al. (2014). Aggressive behavior problems in children with autism spectrum disorders: Prevalence and correlates in a large clinical sample. Research in Autism Spectrum Disorders, 8, 1121-1133.

Ishibashi, T., Horisawa, T., Tokuda, K., Ishiyama, T., Ogasa, M., Tagashira, R., et al. (2010). Pharmacological profile of lurasidone, a novel antipsychotic agent with potent 5-hydroxytryptamine 7 (5-HT7) and 5-HT1A receptor activity. Journal of Pharmacology and Experimental Therapeutics, 334, 171-181.

Kaat, A. J., Lecavalier, L., \& Aman, M. G. (2014). Validity of the aberrant behavior checklist in children with autism spectrum disorder. Journal of Autism and Developmental Disorders, 44, 1103-1116.

Kolevzon, A., Lim, T., Schmeidler, J., Martello, T., Cook, E. H., Jr, \& Silverman, J. M. (2014). Self-injury in autism spectrum disorder: An effect of serotonin transporter gene promoter variants. Psychiatry Research, 220, 987-990.

Lai, M. C., Lombardo, M. V., \& Baron-Cohen, S. (2014). Autism. Lancet, 383, 896-910.

Lecavalier, L. (2006). Behavioral and emotional problems in young people with pervasive developmental disorders: Relative prevalence, effects of subject characteristics, and empirical classification. Journal of Autism and Developmental Disorders, 36, 1101-1114.

Lecavalier, L., Leone, S., \& Wiltz, J. (2006). The impact of behaviour problems on caregiver stress in young people with autism spectrum disorders. Journal of Intellectual Disability Research, 50, 172-183.

Lesch, K. P., \& Merschdorf, U. (2000). Impulsivity, aggression, and serotonin: a molecular psychobiological perspective. Behavioral Sciences \& The Law, 18, 581-604.

Loebel, A., Cucchiaro, J., Silva, R., Kroger, H., Hsu, J., Sarma, K., \& Sachs, G. (2014a). Lurasidone monotherapy in the treatment of bipolar I depression: A randomized, double-blind, placebocontrolled study. American Journal of Psychiatry, 171, $160-168$.

Loebel, A., Cucchiaro, J., Silva, R., Kroger, H., Sarma, K., Xu, J., \& Calabrese, J. R. (2014b). Lurasidone as adjunctive therapy with lithium or valproate for the treatment of bipolar I depression: A randomized, double-blind, placebo-controlled study. American Journal of Psychiatry, 171, 169-177. 
Lord, C., Rutter, M., \& Le Couteur, A. (1994). Diagnostic interviewrevised: A revised version of a diagnostic interview for caregivers of individuals with possible pervasive developmental disorders. Journal of Autism and Developmental Disorders, 24, 659-685.

Mandell, D. S. (2008). Psychiatric hospitalization among children with autism spectrum disorders. Journal of Autism and Developmental Disorders, 38, 1059-1065.

Marcus, R. N., Owen, R., Kamen, L., Manos, G., McQuade, R. D., Carson, W. H., \& Aman, M. G. (2009). A placebo-controlled, fixed-dose study of aripiprazole in children and adolescents with irritability associated with autistic disorder. Journal of the American Academy of Child and Adolescent Psychiatry, 48, 1110-1119.

McCracken, J. T., McGough, J., Shah, B., Cronin, P., Hong, D., Aman, M. G., et al. (2002). Risperidone in children with autism and serious behavioral problems. New England Journal of Medicine, 347, 314-321.

McDougle, C. J., Scahill, L., Aman, M. G., McCracken, J. T., Tierney, E., Davies, M., et al. (2005). Risperidone for the core symptom domains of autism: Results from the study by the autism network of the research units on pediatric psychopharmacology. American Journal of Psychiatry, 162, 1142-1148.

Meltzer, H. Y., Cucchiaro, J., Silva, R., Ogasa, M., Phillips, D., Xu, J., et al. (2011). Lurasidone in the treatment of schizophrenia: a randomized, double-blind, placebo- and olanzapine-controlled study. American Journal of Psychiatry, 168, 957-967.

Millard, P. H., McLaren, J. L., \& Coffey, D. B. (2014). Lurasidone treatment in a child with autism spectrum disorder with irritability and aggression. Journal Child and Adolescent Psychopharmacology, 24, 354-356.

Moore, T., Scarpa, A., \& Raine, A. (2002). A meta-analysis of serotonin metabolite 5-HIAA and antisocial behavior. Aggressive Behavior, 28, 299-316.

Murphy, G. H., Beadle-Brown, J., Wing, L., Gould, J., Shah, A., \& Holmes, N. (2005). Chronicity of challenging behaviours in people with severe intellectual disabilities and/or autism: A total population sample. Journal of Autism and Developmental Disorders, 35, 405-418.

Nakamura, M., Ogasa, M., Guarino, J., Phillips, D., Severs, J., Cucchiaro, J., \& Loebel, A. (2009). Lurasidone in the treatment of acute schizophrenia: A double-blind, placebo-controlled trial. Journal of Clinical Psychiatry, 70, 829-836.

Nasrallah, H. A., Silva, R., Phillips, D., Cucchiaro, J., Hsu, J., Xu, J., \& Loebel, A. (2013). Lurasidone for the treatment of acutely psychotic patients with schizophrenia: A 6-week, randomized, placebo-controlled study. Journal of Psychiatric Research, 47, 670-677.

Newton, J. T., \& Sturmey, P. (1988). The aberrant behaviour checklist: A British replication and extension of its psychometric properties. Journal of intellectual Disability Research, 32, 87-92.

Ono, Y. (1996). Factor validity and reliability for the Aberrant Behavior Checklist-Community in a Japanese population with mental retardation. Research in Developmental Disabilities, 17, 303-309.

Owen, R., Sikich, L., Marcus, R. N., Corey-Lisle, P., Manos, G., McQuade, R. D., et al. (2009). Aripiprazole in the treatment of irritability in children and adolescents with autistic disorder. Pediatrics, 124, 1533-1540.

Politte, L. C., Henry, C. A., \& McDougle, C. J. (2014). Psychopharmacological interventions in autism spectrum disorder. Harvard Review of Psychiatry, 22, 76-92.

Scahill, L., McDougle, C. J., Williams, S. K., Dimitropoulos, A., Aman, M. G., McCracken, J. T., et al. (2006). Research Units on Pediatric Psychopharmacology Autism Network: Children's Yale-Brown Obsessive Compulsive Scale modified for pervasive developmental disorders. Journal of the American Academy of Child and Adolescent Psychiatry, 45, 1114-1123.

Seo, D., Patrick, C. J., \& Kennealy, P. J. (2008). Role of serotonin and dopamine system interactions in the neurobiology of impulsive aggression and its comorbidity with other clinical disorders. Aggression and Violent Behavior, 13, 383-395.

Sheehan, D. V., Sheehan, K. H., Shytle, R. D., Janavs, J., Bannon, Y., Rogers, J. E., et al. (2010). Reliability and validity of the mini international neuropsychiatric interview for children and adolescents (MINI-KID). Journal of Clinical Psychiatry, 71, 313-326.

Siegel, M., Doyle, K., Chemelski, B., Payne, D., Ellsworth, B., Harmon, J., et al. (2012). Specialized inpatient psychiatry units for children with autism and developmental disorders: A United States survey. Journal of Autism and Developmental Disorders, 42, 1863-1869.

Siever, L. J. (2008). Neurobiology of aggression and violence. American Journal of Psychiatry, 165, 429-442.

Simonoff, E., Pickles, A., Charman, T., Chandler, S., Loucas, T., \& Baird, G. (2008). Psychiatric disorders in children with autism spectrum disorders: Prevalence, comorbidity, and associated factors in a population-derived sample. Journal of the American Academy of Child and Adolescent Psychiatry, 47, 921-929.

Simpson, G. M., \& Angus, J. W. S. (1970). A rating scale for extrapyramidal side effects. Acta Psychiatrica Scandinavica, 212S, 11-19.

Volkmar, F., Cook, E. H., Jr, Pomeroy, J., Realmuto, G., \& Tanguay, P. (1999). Practice parameters for the assessment and treatment of children, adolescents, and adults with autism and other pervasive developmental disorders. American Academy of Child and Adolescent Psychiatry Working Group on Quality Issues. Journal of the American Academy of Child and Adolescent Psychiatry, 38(12 suppl), 32S-54S.

Volkmar, F., Siegel, M., Woodbury-Smith, M., King, B., McCracken, J., \& State, M. (2014). American academy of child and adolescent psychiatry (AACAP) committee on quality issues (CQI): Practice parameter for the assessment and treatment of children and adolescents with autism spectrum disorder. American Academy of Child \& Adolescent Psychiatry, 53, 237-257. 